\title{
¿QUÉ ES "FILOSOFÍA CONTEMPORÁNEA"? (LA UNIDAD DE LA FILOSOFÍA CONTEMPORÁNEA DESDE EL PUNTO DE VISTA DE LA HISTORIA DE LA FILOSOFÍA)
}

\author{
Mario Ariel GONZÁLEZ PORTA ${ }^{1}$
}

- RESUMEN: La filosofía del siglo XX se ha escindido en dos tradiciones que, a menudo y, las mas de las veces puramente de fato, se consideran inconmensurables. Los últimos veinte años parecen anunciar la reversión de esta tendencia. El presente trabajo efectúa un aporte en tal dirección, en la medida en que propone un nuevo modo de considerar la reflexión contemporánea en su conjunto: análisis lógico y fenomenología-hermenéutica son aspectos de un único y mismo giro (turn) en la historia de la filosofía. De este modo, no solo se rescata la unidad del pensamiento contemporáneo, sino que se ilumina su continuidad con la historia de la filosofía.

- PALABRAS-CLAVE: Historia de la filosofía; filosofía contemporánea; filosofía analítica; fenomenología; hermenéutica.

\section{Introducción}

En este artículo me propongo ofrecer un primer esbozo de respuesta a la pregunta, ¿qué debemos entender por “filosofía contemporánea?”. Sobre éste punto existe una gran indeterminación; siendo absolutamente imposible para el lego, es difícil, incluso para el estudioso, formarse una idea apropiada de la reflexión filosófica del siglo XX en su conjunto. Si nos queremos ayudar, comparando obras especializadas al respecto, la

1 Professor do Programa de Pós-Graduação em Filosofia da PUC/SP. 
situación no mejora sustancialmente: autores que en una son considerados fundamentales, simplemente ni aparecen en la otra. En la base de ésta indeterminación hay un fenómeno digno de ser reflexionado, a saber: "la" filosofia contemporánea parece no tener unidad y abarcar dos desenvolvimientos independientes e, incluso, inconmensurables.

Desde la virada del siglo la filosofía se desenvolvió en el marco de una división esquizoide. "Analíticos", por un lado, y "fenomenólogoshermenéutas", por otro, parecieron durante mucho tiempo no tener nada que aprehender unos de otros y, lo que es aún peor, ni siquiera de qué conversar. Si la filosofía, desde siempre, poseyó escuelas y tendencias y, si estas llegaron en ocasiones a un alto grado de rivalidad, el simple indiferentismo, en el marco de una convivencia desconfiada, es un fenómeno característicamente contemporáneo. Las dos o tres últimas décadas anuncian una reversión de esta tendencia, aún cuando, no obstante, estamos aún lejos de que la misma sea recepcionada por los amplios círculos.

Si mi objetivo es esclarecer el concepto de "filosofía contemporánea", importa desde ya observar que me propongo cumplir ésta tarea a partir de la consideración de la historia de la filosofía, para lo cual, claro está, ésta debe ser pensada en perspectiva "filosófica". Podemos usar diferentes principios para secuenciar la historia de la filosofía. El más común, surge de correlacionar la misma a los períodos históricos, políticos y culturales. Así, se obtiene una ordenación en filosofía antigua, medieval, moderna y contemporánea. Común a éste, y otros principios, es el que ellos son extrínsecos, y distinguen fases en la historia de la filosofía sobre la base de puntos de vista de naturaleza no-filosófica. Lo que aquí nos interesa es, no obstante, intentar ordenar el desenvolvimiento filosófico por criterios que sean, en primer lugar, propiamente filosóficos $\mathrm{y}$, en segundo lugar, "dinámicos", esto es, que permitan comprender no sólo la diferencia esencial entre los varios momentos sino, asimismo, la razón interna del pasaje de uno a otro. Para fijar los mismos, parto del convencimiento de que lo esencial en el estudio filosófico es la determinación de los problemas. ${ }^{2}$ Filosofar no es asunto de inspiración. La filosofía siempre se construye a partir de su propia historia, no importa a través de qué caminos el pensador particular recepcione ésta. "Originalidad" en filosofía es invariablemente consecuencia de una adecuada percepción

2 El entender la filosofía como discurso "argumentativo" (algo usual en círculos analíticos) presupone el entenderla como "solución de problemas". Sobre éste punto véase más adelante.

3 Justamente porque considero la filosofía del modo mencionado, dada la facticidad de su sujeto, también la considero como esencialmente histórica. No me parece haber aquí contradicción alguna. 
de cual es el próximo movimiento posible (o necesario) en un proceso que posee un carácter "evolutivo". ${ }^{4}$ Lo que determina este proceso es la dinámica interna de los problemas. El criterio que buscamos aquí debe, sobre la base de establecer una interrogante fundamental, fijar también, asimismo, cual es el concepto y cual la disciplina básica de la filosofía en un período dado 5 .

\section{Período metafísico}

En un primer momento, el interés del pensamiento está dirigido al "mundo", incluya este mundo o no el propio hombre. Los filósofos se preguntan por lo que hay y por lo que no hay o, qué tipos de cosas hay y de qué se componen o, cómo es lo real. La disciplina filosófica fundamental del período es la metafísica (u ontología) y el concepto fundamental el de "Ser". Nombres representativos de este momento son Platón, Aristóteles, Sto. Tomás, etc.

En el período metafísico, la filosofia es un discurso sobre objetos. Una forma refinada de esta idea, pero no la única posible, es que se trata de un discurso sobre objetos de tipo particular, por ejemplo, suprasensibles o no-empíricos. ${ }^{6}$

Ahora bien, desde siempre la filosofía no se ha preguntado meramente por lo que es, sino también por lo que debe ser, no sólo por los principios del ente, sino por los principios de la acción o, más concreta-

\footnotetext{
4 Esta "evolución" no debe ser entendida como "progreso" en el sentido de acúmulo de conocimientos o aproximación a una cierta verdad, sino como clarificación creciente de aquello que pensamos. Véase adelante.

5 Concedo, primero, que haya otras formas ordenadores posibles; mas ya el hecho de disponer de una, no arbitraria, es importante. Segundo, el criterio propuesto no agota todas las cuestiones: siempre se pueden marcar excepciones o casos dudosos. Finalmente, el puede ser mejorable respetando los principios básicos enunciados.

6 Para evitar un grosero equívoco, conviene una precisión. En ningún momento pretendo decir que en el período metafísico no se tematizen también cuestiones epistemológicas o semánticas. Un rápido vistazo a las obras de Platón, Aristóteles o Sto. Tomás, proporcionaría claros ejemplos en tal sentido. De la misma forma, en el período epistemológico también se abordan cuestiones ontológicas y semánticas y, en el contemporáneo, ontológicas y epistémicas. No obstante, no se trata de esto. De lo que se trata es del modo de concebir la filosofia, de la fijación de aquello que es esencial para que un discurso sea llamado de "filosófico" $y$, con ello, de la perspectiva unitaria a partir de la cual la diversidad de las cuestiones son abordadas. Así, por ejemplo, la riquísima elaboración de la semántica entre los filósofos medievales no altera el hecho de que ellos no entendieron la filosofía como semántica, sino básicamente como ontología, preocupada en primera línea en pensar un ser extremamente especial: Dios. Sin apelar a la idea de un ser supremo no se puede entender lo que para un medieval era "filosofía".
} 
mente, por los criterios para diferenciar cuando actúo bien y cuando mal. A la disciplina filosófica que se ocupa con éste asunto la denominamos "ética". En el período metafísico la fundamentación de la ética está indisociablemente unida a una metafísica. Lo que debo o no debo, depende de lo que és o no es; por ejemplo, el cómo me debo comportar, es establecido por Dios.

\section{Período trascendental}

En el período epistemológico, ${ }^{7}$ en vez de preguntarse por el objeto, la filosofía pasa a preguntarse por nuestro conocimiento del mismo. $\mathrm{La}$ epistemología deviene disciplina fundamental y la verdad el concepto clave. Esta virada, característica de la modernidad, comienza con Descartes y culmina con Kant, con quien adquiere su forma más pura y consecuente. Si en Descartes, en última instancia, y pese a toda "subjetividad", Dios jugaba un papel esencial en la fundamentación del conocimiento, con Kant éste ya no se legitima a partir de una instancia externa, sino a partir de sí mismo.

En el período epistemológico el discurso de los filósofos deja de ser un discurso sobre objetos, para pasar a ser un discurso sobre el conocimiento de los objetos. La pregunta no concierne ahora a "lo que hay", sino al saber de lo que hay: si puedo conocer, dentro de qué límites, qué cosas, de qué forma y, eventualmente, cual es el fundamento del conocimiento (la experiencia o una fuente no-empírica, la razón, la intuición pura, etc.).

¿Porqué se pasa del primero al segundo período? ¿Se trata, simplemente, de una substitución casual de temas, de un cambio arbitrario de interés, o hay un principio interno en la evolución de los propios problemas, que conduce del uno al otro? Sin duda es esto último lo que acontece. "Antes"8 de preguntarnos por "lo que hay", debemos preguntarnos si podemos conocer "lo que hay". Formular la pregunta por "lo que hay", presupone que se puede conocerlo. Ahora bien, justo en la medida en que éste presupuesto se efectúa, surgen las dificultades: eventualmente, la contradicción de teorías posibles, la falta de argumentos satisfactorios, la

\footnotetext{
7 Clarifico inmediatamente porqué, en el subtítulo, se habla de período "trascendental" y luego, en el texto, de "epistemológico".

8 Este "antes" no es ciertamente temporal, sino lógico.
} 
necesidad de criterios. En suma, la pregunta epistemológica es más fundamental que la metafísica, puesto que ésta supone lógicamente aquella.

El cambio que se produce en el ámbito teórico de la metafísica a la epistemología, tiene un paralelo en el cambio que se produce en el ámbito práctico en la relación entre metafísica y ética. Con respecto al "deber ser", acontece algo similar a aquello que ya vimos con respecto al conocimiento: la ética deja de fundarse en un principio externo y pasa a fundarse en la Razón.

Si tomamos conjuntamente lo acontecido en la teoría del conocimiento y en la ética, diremos que la filosofía, en su pasaje de la "heteronomía a la autonomía", deviene teoría de la validez (Geltungstheorie), sea ésta validez (Geltung), la de la verdad en el campo teórico o la del bien en el práctico. La filosofía ya no es más un discurso sobre objetos (como lo era en el periodo anterior), sino sobre la "objetividad", o sea, sobre las condiciones de posibilidad del "objeto". Por "objetividad" (o "validez") entenderemos básicamente "ínter subjetividad" - no ciertamente en el sentido de una mera comunidad de sujetos fácticos cualquiera sino, en el caso límite, de sujetos racionales posibles. "Validez" quiere decir válido universalmente. Un discurso que no habla de "objetos", sino de sus condiciones de posibilidad, es lo que en filosofía se acostumbra a calificar de "trascendental". Un discurso de este tipo procura la fundamentación de las aspiraciones de validez universal, sea con respecto a la verdad de lo que es (teoría del conocimiento), sea con respecto a la legitimidad de lo que debe ser (ética).

\section{La filosofía contemporánea}

Ya vimos que, en la tercera etapa, tenemos un fenómeno sui géneris de escisión de la filosofía en dos tradiciones (analítica y fenomenológico-hermenéutica). Por tal motivo, comenzaremos preguntando por cada una da ellas por separado para, recién entonces, pasar a considerar su relación. ${ }^{9}$

\footnotetext{
9 Dado que las tendencias referidas experimentan una intensa evolución, he optado por situar en primer plano lo que podríamos llamar "momento fundacional" de las mismas, haciendo breve mención a algún desarrollo decisivo que no sea sin más comprensible a partir de él.
} 


\section{La filosofía analítica}

Comencemos nuestra exposición con respecto a la filosofía analítica distinguiendo entre el "sentido" 10 y el "valor de verdad" de un enunciado. Un "enunciado" es una formulación lingüística efectiva (oral o escrita) que puede ser declarada verdadera o falsa como, por ejemplo: "El auto de Juan es verde". Verdadero y falso es lo que llamamos "valores de verdad". Cada enunciado tiene uno de estos dos valores de verdad: o él es verdadero, o él es falso. El sentido del enunciado es lo que él significa, "dice" o afirma.

Es un mérito histórico de Frege el haber trazado de modo claro y preciso la línea divisoria entre las nociones de sentido y valor de verdad, ${ }^{11}$ pensando consecuentemente sus implicaciones..$^{12}$ Ahora bien, tan simple y habitual como esta distinción nos pueda hoy parecer, tan trabajoso fue su establecimiento y tan fecundas son sus derivaciones. ${ }^{13}$ Ella no sería posible sin la toma de conciencia de la especificidad del significado y, de modo correlativo, por un lado, de la crítica al psicologismo, por otro, de la elaboración del concepto de objetividad no real, del cual el significado es una instancia particular. ${ }^{14}$ Sin ella, asimismo, no podría existir ni "semantic turn" ni "filosofía analítica".

Establecer la delimitación del sentido frente al valor de verdad es una condición negativa necesaria del surgimiento del "semantic turn"; ella no es suficiente, sin embargo, para dar cuenta del mismo. Según nuestra hipótesis general, la etapa tres no meramente sigue a la dos, sino que deriva de la misma por una evolución interna. ¿Porqué se pasa del período epistemológico al semántico? A esta pregunta podemos ofrecer tres respuestas, con grados diversos de precisión y accesibilidad intuitiva:

10 Uso indiferentemente los términos "sentido", "significado" y "significación" (Sinn, Bedeutung, Bedeutsamkeit, Meaning), optanto por uno u otro, según el caso, por meras razones estéticolingüísticas.

11 Los esfuerzos de Bolzano al respecto cayeron en el olvido.

12 El modo en que el la traza, no obstante, es diferente del expuesto por nosotros. Según Frege, lo que es propiamente verdadero o falso no es el enunciado, sino su sentido, concebido como una cierta entidad existente en sí. De todas formas no son las particularidades lo que interesa ahora, sino el propio distingo en cuanto tal.

13 Refinadas teorías y complejas estructuras conceptuales se basan, en última instancia, en esta simple distinción.

14 No importa que, ulteriormente, la significación pudiera ser pensada sin tales presupuestos; para poder fijar su concepto, estos son necesarios. 
1 En la versión más simple, partamos de observar que somos seres eminentemente lingüísticos, esto es, que usamos lenguaje y que este uso es condición de la producción y transmisión de conocimientos. El hecho indicado es tan obvio, que resulta incomprensible que los filósofos pudieran ignorar o subestimar su importancia durante siglos, colocando sus teorías en el marco de presupuestos que implican que los sujetos epistémicos no hablan o sólo lo hacen de modo contingente.

2 Si el estado de cosas apuntado es de extrema relevancia, el no contiene, no obstante, necesidad conceptual alguna; pero es una tal, la que estamos buscando. Para que un enunciado tenga valor de verdad, es necesario

a) que él tenga un sentido,

b) que él tenga un sentido y sólo uno (o sea, no varios),

c) y que sea uno preciso (o sea, uno definido, no vago).

De lo anterior se sigue:

a) El sentido de un enunciado es independiente de su valor de verdad y no se altera por éste.

b) El valor de verdad de un enunciado no es independiente de su sentido. ${ }^{15}$

c) El sentido del enunciado es, por tanto, condición de posibilidad de su valor de verdad $\mathrm{y}$, en consecuencia, su establecimiento antecede lógicamente a la fijación de éste.

En suma, al problema moderno del conocimiento se antepone ahora un otro, más fundamental, pues lógicamente anterior, el problema de la significación o semántica. ${ }^{16}$

3 Podemos establecer una línea de exposición más accesible al lector no-especialista si, en vez de asumir una perspectiva semántico-objetiva, que es la propia de la filosofía analítica, introducimos una "subjetiva". ${ }^{17} \mathrm{Se}$

15 En situaciones excepcionales, el es determinado de modo exclusivo por éste, por ejemplo, en el llamado "juicio analítico".

16 En el marco de las anteriores consideraciones, la cuestión epistemológica ciertamente no se pierde, pero se transforma en la referente al valor de verdad, implicando la importante decisión de qué sea aquello que de modo originario posee la propiedad de ser verdadero. Algo similar debe decirse con respecto a la temática de la trascendentalidad y aprioridad. Si en el período epistemológico las mismas están referidas a las relaciones de valores de verdad, a partir de ahora se torna necesario desenvolverlas en un nuevo plano.

17 Es obvio que, lo que ésta oposición realmente signifique, no puede ser aclarado aquí. 
puede "entender" un enunciado sin saber si él es verdadero o falso. Por ejemplo, yo puedo entender lo que quiere decir Juan, cuando afirma que su nuevo auto es verde, aun cuando no sepa si realmente lo es o no. ${ }^{18}$ Ahora, la situación inversa no es posible: yo no puedo saber si un enunciado es verdadero, si no entiendo su sentido. Conocer es atribuir valores de verdad, entender es captar sentidos. Entender un enunciado es una condición necesaria de saber si él es verdadero, o sea, de conocer si lo que él dice es el caso.

De lo expuesto hasta ahora queda en claro que el punto central que marca el pasaje del período epistemológico al semántico es la prioridad lógica (y sólo por derivación "psicológica") de la temática de la significación con respecto a la del valor de verdad. Consecuencia de esto es que la semántica deviene disciplina filosófica fundamental, ocupando el lugar privilegiado que una vez correspondió a la epistemología o a la metafisica. Los problemas principales a ser resolvidos por esta disciplina son:

a) ¿En qué consiste la significación de un enunciado?

b) ¿Cuál es el vínculo entre la significación del enunciado como un todo y la de sus partes componentes?

c) ¿Cuando un enunciado tiene significación y cuando no lo tiene? ¿Cuál es, en general, la línea demarcatoria entre sentido y sin sentido?

d) ¿Qué es lo que vincula la significación del enunciado a la "realidad"? ¿Cuál es la relación entre la significación del enunciado y el mundo?

Sin que lo expuesto anteriormente deje de ser verdadero, la novedad fundamental introducida por la filosofía analítica puede ser vista de un otro modo. La filosofía analítica no es tan sólo la fijación de un nuevo tema u objeto del filosofar sino, básicamente, de un método: el análisis lógico del lenguaje. La filosofía ya no es un discurso ni sobre objetos, ni sobre nuestro conocimiento de objetos, sino sobre el lenguaje en el cual hablamos de los objetos. El análisis lingüístico, sin embargo, es de modo esencial una praxis, la praxis de esclarecimiento del sentido, y no, necesariamente, una "teoría" (o sea, un conjunto sistematizable de verdades con respecto a una cierta cuestión). La filosofía ahora no sólo no es un discurso sobre "objetos" o sobre "objetividad" sino que, en ciertas variantes radicales, tampoco es "teoría" de la significación. Ella simplemente

\footnotetext{
18 Está fuera de discusión la capacidad del lenguaje de producir nuevas significaciones, así como la del sujeto lingüístico de decirlas y entenderlas.
} 
deja de ser concebida como "teoría" y pasa a ser pensada como actividad elucidadora.

En lo expuesto hasta ahora el lector habrá quizá percibido un cierto oscilar entre los conceptos de "significado" y "lenguaje". Esta impresión no es infundada y se debe a que el vínculo entre ambos es esencial en la filosofía analítica, quedando en claro a partir de Frege que sólo tenemos acceso a la significación a través del substrato sensible del signo lingüístico y, en consecuencia, que únicamente por medio del análisis del lenguaje es posible un análisis de los pensamientos (Gedanken). ${ }^{19}$ En evoluciones posteriores, el lenguaje ya no será un instrumento para la captación de un cierto x extra-lingüístico, la significación, sino que ésta pasa a ser concebida como siendo algo intra lingüístico.

Uno de los resultados fundamentales del análisis lógico es el "disolver" lingüísticamente pretendidos problemas "metafísicos", evidenciando que los mismos carecen de sentido. En este punto se puede ver con ejemplar claridad la diferencia básica entre la filosofía trascendental y la analítica: la crítica kantiana de la metafísica era epistemológica, la analítica es semántica. Para Kant, no podemos decidir el valor de verdad de ciertos enunciados aún cuando, sin duda, ellos son significativos; para la filosofía analítica, no podemos decidir el valor de verdad de ciertos enunciados porque la condición necesaria para ello está ausente, o sea, porque los mismos carecen de sentido.

\section{La hermenéutica}

Así como Frege es decisivo para el "giro" (turn) lingüístico-semántico, Dilthey lo es para el hermenéutico. Su programa de superación correlativa de las filosofías empirista e idealista debilita de modo irreversible el monismo epistemológico, estableciendo la existencia de dos tipos de ciencias, con objetivos y métodos diferentes. Las ciencias de la naturaleza (Naturwissenschaften) procuran explicar (Erklären), o sea, establecer leyes y derivar estas leyes de otras; las ciencias del espíritu (Geis-

19 Para ser precisos, tendríamos que distinguir la "virada lingüística" (linguistic turn) de la "virada semántica" (semantic turn), situando el orígen de la primera en Mill, el de la segunda en Bolzano. La diferencia entre ambas es que ésta última, no casualmente surgida del ámbito cultural germánico, trabaja en base al concepto de "entidades intensionales". Constatar lo anterior no implica desconocer que de la preocupación con el significado no se sigue de modo necesario un compromiso "realista", debiéndose admitir la posibilidad de teorías puramente referenciales del mismo. 
teswissenschaften), por el contrario, procuran comprender (Verstehen), o sea, captar un significado. Esto supone partir de una "expresión" (Ausdruck) u "objetivación" del espíritu (pintura, novela, monumento, sinfonía, acto, personalidad histórica), para remontarse a la vivencia (Erlebnis) de la cual ella se origina y en la cual se sustenta. En esta, su primera versión, el aprehender un sentido tiende a ser asimilado, pues, a una “identificación vivencial". Las implicaciones psicologistas de tal postura habrán de merecer la crítica de sus contemporáneos, conduciendo Dilthey a sucesivas reformulaciones de su teoría primitiva que tienden a considerar crecientemente lo entendido en cuanto tal. El mismo, no obstante, jamás se independiza de modo absoluto del comprender, ni deviene una entidad existente en sí. Esto no es un hecho secundario, sino que responde a un motivo esencial: la "comprensión" implica algo más que un vínculo puramente cognitivo con un "objeto"; el individuo en cuanto totalidad está comprometido en la misma. El sujeto deviene "Vida" (Leben), el objeto "Mundo" (Welt).

En principio - y a diferencia de la semántica -, la hermenéutica no parece ser una superación radical de la teoría del conocimiento moderna, sino tan sólo su complemento, limitándose su aporte a la propuesta de un nuevo "método científico", concurrente del físico. En su desarrollo, no obstante, ella explicita su verdadero potencial, reformulando la propia idea de filosofía. Tenemos que dirigir al período hermenéutico la misma pregunta que ya hemos dirigido a los anteriores: ¿porqué se pasa al mismo? Así como, en la filosofía analítica, se reconoce el sentido como condición del valor de verdad, en la hermenéutica, el "entender" deviene condición del "saber. ${ }^{20}$ El conocimiento aparece ahora como un modo derivado de vincularse al mundo que no puede ser concebido a partir de sí, sino a partir de la "Vida" (Leben). Únicamente sobre el trasfondo de una comprensión originaria del mundo como totalidad hay conocimiento. ${ }^{21}$

La "Vida" no es un evento biológico, ni puede ser comprendida a partir de una conceptualidad de tal tipo. Significación (Bedeutung), significatividad (Bedeutsamkeit) y contexto (Zusammenhang) son los conceptos básicos o categorías (Lebenskategorien) a partir de los cuales ella deviene inteligible. La primera mencionada ocupa un lugar diferenciado frente al resto: "Vida" es el ámbito originario de la significación (Bedeu-

20 Claro está que ese "entender" no siempre es captación del significado de "proposiciones".

21 La hermenéutica posterior a Dilthey experimentará una significativa evolución en torno de esta idea fundamental. 
tung); significación, el correlato esencial de la "Vida". No hay "Vida" sino allí donde hay significación. La hermenéutica, en cuanto teoría de la interpretación y comprensión, no sólo substituye a la teoría del conocimiento, sino que exige un fundamento más originario; la filosofía de la Vida ( $\mathrm{Le}$ bensphilosophie) pasa a ocupar el lugar de la filosofía trascendental.

Tal como ella se presenta ya en su creador, la hermenéutica contiene una prioritaria vocación metódica y una renuncia al "sistema" (System). Idea esencial de Dilthey es el abandono de cualquier "punto arquimédico", o sea, de todo Absoluto a partir del cual se pudiese proceder "fundacional-" o "cartesianamente". El comienzo (Anfang) de toda reflexión es la pura facticidad (Faktizität), no siendo posible superar el punto de vista de la finitud mediante el movimiento reflexivo. Facticidad no puede ser ni deducida ni demostrada sino, únicamente, "comprendida". La "fundamentación" es sustituida por la "explicitación". La filosofía, en cuanto Lebensphilosophie, deviene actividad de explicitación de estructuras significativas. ${ }^{22}$

\section{La fenomenología}

En la exposición del numeral precedente no hemos mencionado la fenomenología mientras que, con anterioridad, siempre nos referimos a ella conjuntamente con la hermenéutica. Esto no es producto del descuido, sino de una distinción necesaria de cuestiones. Hermenéutica y fenomenología tienen orígenes históricos independientes. No obstante, es un hecho innegable el que, a partir de un cierto momento, un complejo juego de influencias se desenvuelve entre ellas. El interés recíproco de Husserl y Dilthey, por un lado y, por otro, la explícita reformulación de la fenomenología como hermenéutica en Heidegger, son claros elementos en tal sentido. Si atendemos a lo dicho, es innegable que el vínculo entre estas dos corrientes de la filosofía contemporánea es diferenciado frente al que existe entre ellas y la filosofía analítica, estando ausente en un caso, la ruptura que se constata en el otro. Los elementos indicados son suficientes para, desde el punto de vista de la historia del pensamiento, otorgar a hermenéutica y fenomenología un tratamiento común, contraponiéndolas conjuntamente a la filosofía analítica. Sin embargo, y contra la autoridad de Heidegger, hermenéutica y fenomenología no son lo mismo y la

22 Algo comparable a lo que, según ya vimos, puede acontecer en el análisis lingüístico. 
pregunta por sus vínculos, sobre todo desde el punto de vista metódico, es una cuestión compleja que, sin desconocer confluencias, impide la simple asimilación, sea esta unilateral o recíproca. Si se concede lo anterior, es claro que si la fenomenología tiene que ser entendida como momento del cambio de paradigma de la teoría del conocimiento a la del significado, lo tiene que ser por sí misma, y no por su vínculo a la hermenéutica. $^{23}$

Que la fenomenología contiene "también" una "teoría de la significación”, ${ }^{24}$ se puede conceder sin mayores discusiones. En efecto, significado (Bedeutung), Noema, sentido (Sinn), constitución de sentido (Sinnkonstitution), donación de sentido (Sinngebung), no menos que expresión (Ausdruck) y comprensión (Verstehen), son parte esencial y no dispensable de su repertorio conceptual. Sin embargo, esto no legitima el interpretar a la fenomenología como siendo teoría de la significación y, por tanto, como un momento más en el cambio de paradigma que analizamos.

Los elementos esenciales para otorgar una respuesta afirmativa en este punto parecen ser los siguientes:

1 En primer lugar, se trata de la propia idea de "método fenomenológico" y de su objeto, el cual, en definitiva, es el objeto de la fenomenología misma. El "método fenomenológico" no visa "lo real", el cual debe quedar "entre paréntesis", sino la esencia, o sea, según la explícita definición de Husserl, “unidades ideales de significación”. Esto implica que la temática de la "objetividad" deja de ser referida de modo exclusivo a las aspiraciones de validez, para trasladarse, no sólo "también", sino de modo prioritario a la significación. A partir de ahora es establecida una nueva exigencia a toda filosofía que pretenda el título de "trascendental" la fundamentación de la objetividad ya no puede limitarse a los criterios resolutivos de valores de verdad. Ella debe pasar, de una forma u otra, por la temática de la "objetividad de la significación" y, en general, de las "idealidades". Así como el noema es condición de posibilidad de toda referencia objetual, ${ }^{25}$ la temática de la constitución de sentido (Sinnkonstitution) debe "anteceder", desde el punto de vista sistemático riguroso, a la de la constitución de "objetos" (Gegenstandskonstitution). Este nuevo pro-

\footnotetext{
23 El uso del término "paradigma" no supone suscribir la tesis de Thomas Kuhn con respecto a la evolución de la ciencia ni pretende extender la misma a la filosofía.

24 Siguiendo el desconforto husserliano, evito llamar a la misma de "semántica".

25 En una otra variante, históricamente no ajena a la anterior, el mismo orden de cosas se encuentra en la hermenéutica.
} 
blema de la validez no está presente en Kant, tornándose posible y necesario a partir de Frege y su concepto de "tercer reino" (drittes Reich).

2 Sin embargo, la afirmación de un reino de "objetividades", nos dejará siempre con la mitad de la cuestión. La pregunta por la subjetividad no es una pregunta husserliana entre otras, sino momento esencial del sentido originario de la interrogación fenomenológica. Tarea básica de la misma es el dar cuenta del "pasaje de lo subjetivo a lo objetivo" o de la "aprehensión" (Auffassen) de lo "objetivo" a partir de lo subjetivo, siendo su concepto neural, la "intencionalidad", momento clave de la respuesta. Ya Frege tiene explícita conciencia de este problema y un claro lineamento respecto a su solución: si la idea fenomenológica de intencionalidad posee en Brentano un contrapunto, ella tiene en Frege un antecedente.

3 Las dos perspectivas, la "objetiva" y la "subjetiva" no están desligadas, sino que se exigen de modo recíproco. Mientras algunos críticos insisten en subrayar la existencia de dos fases en el pensamiento de Husserl, la realista de las "Investigaciones lógicas" y la idealista de "Ideas", otros, por su parte, procuran relativizar la tesis de una oposición radical entre las mismas. Sin embargo, la cuestión realmente básica no es la de decidir esta alternativa, sino la de evidenciar el núcleo común a ambas opciones justamente en cuanto diferentes. La esencialidad de la perspectiva "subjetiva" es propia de las dos fases, sólo manifestándose en cada una de ellas de forma heterogénea: como "aprehensión" (Auffassen) en el período realista, como constitución (Konstitution) en el idealista. Asimismo, ella tampoco está presente sin la objetiva: ámbito esencial de aplicación del método fenomenológico es justamente el vínculo sujeto-objeto. La idea de objetividad no-real es ahora trasladada a la propia relación del sujeto con la objetividad siendo de este modo referida a esencias y abordada a priori. Esta aplicación de la idea de "tercer reino" al propio vínculo sujeto-objeto, no está ni siquiera esbozada en Frege, quien, en este punto, permanece en una posición "precrítica".

\section{Una aproximación sistemática a la cuestión de la unidad del pensamiento contemporáneo en la perspectiva de la historia de la filosofía}

La heterogeneidad entre filosofía analítica, fenomenología y hermenéutica es innegable, al punto que bien podría preguntarse qué sentido 
tiene establecer entre ellas un vínculo que no sea el meramente histórico-cronológico. Nuestra respuesta es simple: porque creemos que, pese a todas las diferencias (que ciertamente no deben ser subestimadas), hay puntos de contacto esenciales que permiten considerarlas como momentos divergentes de un único movimiento o expresiones diversas de un giro (turn) común. Filosofía contemporánea, sea analítica, sea fenomenológica, sea hermenéutica es, de modo esencial y no secundario, "teoría de la significación”. ${ }^{26}$ La centralidad de la temática de la significación es común a las tres tradiciones. ${ }^{27}$

Indicar una confluencia no quiere decir afirmar identidad y, por eso, importa atender al complejo juego de similitudes y diversidades aquí presentes.

\section{Sentido}

El sentido en cuestión en la reflexión analítica es aquel propio de enunciados lingüísticos y posee carácter proposicional. Ventaja del sentido lingüístico-proposicional es permitir una tematización más precisa, tanto del caso concreto, cuanto de la conceptualidad general necesaria para pensar el mismo; el es, no obstante, claro está, limitado.

El concepto de sentido hermenéutico es, sin duda, más amplio. Se trata "también" del sentido de enunciados lingüísticos y estructuras proposicionales, no obstante, asimismo, de actos, de personalidades, de hechos históricos, de objetos culturales de todo tipo y, en general, de "totalidades" y "estructuras". Esta amplitud del concepto hermenéutico de sentido lo compromete en principio con cierta imprecisión. No obstante, si ella es innegable, no se puede pasar por alto el explícito intento de Dilthey en delimitar y articular los diversos modos de significación en una

\footnotetext{
26 Empleo la fórmula "teoría de la significación" sólo por no disponer de otra más adecuada que fuese absolutamente neutra y no sugiriese una de las tradiciones específicas. Por otra parte, surge claramente de lo ya expuesto, que la propia idea de "teoria" no es libre de toda insuficiencia y merece precisiones.

27 El desenvolvimiento que constatamos en la filosofía, tiene una contraparte en la propia evolución de la ciencia. La fisica, más concretamente, la mecánica newtoniana, es el producto paradigmático de la ciencia del siglo XVIII. En el siglo XIX, claro está, las Naturwissenschaften continúan su desarrollo e, incluso, se apartan del modelo newtoniano. Ahora, si atendemos al surgimiento de nuevas ciencias en el siglo XIX, veremos que buena parte de ellas están vinculadas al concepto de significación, como es el caso de la semiótica, la lingüística, el psicoanálisis, la propia lógica y, en algunas concepciones, incluso la historia y la sociología. La cultura contemporánea como un todo, y no sólo la filosofia, tiene en la idea de sentido un eje temático.
} 
teoría unitaria universal de la misma, de la cual el sentido lógicoproposicional representa tan sólo un aspecto. Dilthey diferencia tres formas de “expresión de la Vida" (Lebensausdrücke) (una en sentido propio y dos en sentido amplio), correspondientes e correlacionadas internamente a tres modos del entender (Verstehen) y de la significación (Bedeutung): a) el entender lógico posee como rasgo esencial su carácter no contextual; b) el entender técnico tiene naturaleza teleológica, dirigiéndose a actos que ostentan una finalidad inmanente; c) el entender vivencial, finalmente, que es el correlativo de la "expresión" (Ausdruck) en sentido estricto, supone la manifestación de un interior en un exterior e, inversamente, la interpretación de aquel a partir de éste.

En el caso de la fenomenología, vale en principio algo similar a lo expuesto en el caso de la hermenéutica. Su propio desenvolvimiento la lleva a focalizarse en dos cuestiones de decisiva importancia, no sólo para ella, sino también para las dos tradiciones restantes:

a) ¿Es todo sentido susceptible de una formulación lingüística o hay sentidos que son intrínsecamente extra-lingüísticos?

b) ¿Es todo sentido proposicional (o, por lo menos, proposicionalizable)?

Una forma "técnica" que asume ésta importante discusión, si bien no la única posible, se refiere a la interpretación del noema husserliano.

Si la mencionada más arriba es la postura "clásica" de la filosofía analítica, no podemos pasar por alto que, a partir de la así llamado teoría del significado como uso, y en general, de la creciente valorización de la perspectiva pragmática frente al proyecto original de una semántica "pura", va a surgir una tendencia a entender el sentido lingüístico como caso particular del sentido de actos y, de este modo, como variante de un concepto más abarcador. La así llamada "teoría de la acción" es un desenvolvimiento ulterior en ésta perspectiva, aún cuando, claro está, ella sea metódicamente desenvolvida como una teoría del lenguaje que describe los actos. Bajo tal punto de vista, ciertamente se pueden buscar nuevas aproximaciones entre las tres corrientes que estudiamos.

\section{Variaciones en torno al concepto de sentido}

No meramente el concepto de sentido - por decirlo así, "en abstracto" - es patrimonio común a las tres tradiciones estudiadas, sino un amplio complejo de temas que lo implican, sin ser sin más reducibles al mismo, a saber: a) paralelos conceptuales, b) destaque de ciertas nocio- 
nes y c) trasfondos teóricos similares. Veamos, sin cualquier pretensión a exahustividad, algunos ejemplos.

a) A la distinción analítica entre sentido y referencia, corresponde la fenomenológica entre noema y objeto; al principio semántico de que todo término tiene una referencia, el principio (brentaniano) de que todo acto intencional tiene un objeto; a la temática, surgida en el marco de la teoría referencial de la significación, de términos sin referencia, la cuestión (bolzano-brentaniana) de representaciones sin objeto; a la teoría de las descripciones, la distinción entre contenido (Inhalt) y objeto (Gegenstand) o la teoría de meinongniana de objetos inexistentes; a la noción de predicados de diferente orden, la noción de objetos o, eventualmente, de actos de niveles diversos; a la centralidad del problema del juicio falso, la centralidad del problema de los juicios negativos verdaderos, etc. De modo similar con respecto a semántica y hermenéutica, podemos decir que al "principio de contexto" corresponde la idea de "entramado significativo" (Sinnzusammenhang), a la idea de predicados de segunda orden, la idea de experiencias de segunda orden (que son en Dilthey esenciales para la lógica), etc.

b) En otros casos, mas que de paralelos, se trata del carácter clave que asumen ciertas nociones como, por ejemplo, concepto y objeto, estado de cosas (Sachverhalt) y hecho (Tatsache), el carácter no contextual de la significación lógica y la correlativa posibilidad de desenvolver una semántica pura, ${ }^{28}$ la antecedencia del juicio con respecto al concepto, la negación de que el juicio sea una reunión de representaciones y afirmación de que se trata de una reunión del contenido de las representaciones, diferencia entre concepto (Begriff) y representación (Vorstellung), etc.

c) Finalmente, en otros casos, los puntos de contacto lo constituyen teorías que remiten a trasfondos histórico-sistemáticos similares. Así, tanto la noción de "tercer reino" (drittes Reich), como la diferencia entre la cosa (Ding) y el "ser de la cosa" (Sein des Dinges) y su derivación en la idea de "estados de cosas" (Sachverhalte), como la diferencia entre ser (Sein) y ente (das Seiende), aún cuando ciertamente no son ni idénticas ni paralelas, tienen como marco implícito común la cuestión clásica de la equivocidad del ser.

\section{Subjetivo-objetivo}

\footnotetext{
28 Sería interesante comparar las tesis semánticas y hermenéuticas con respecto al sentido lógico, dejando metódicamente de lado la inserción sistémica de las mismas.
} 
Entre los presupuestos posibilitantes del concepto de significación ocupa un lugar de destaque la llamada polémica en torno al psicologismo. Llamamos psicologismo a toda teoría que, de un modo u otro, reduzca la significación a una entidad psicológica (vivencia (Erlebnis) o representación (Vorstellung)). ${ }^{29} \mathrm{Su}$ crítica, así como, correlativamente, el compromiso con un cierto "platonismo", es un factor clave en el surgimiento tanto de la semántica cuanto de la fenomenología. En el caso de la hermenéutica, como ya vimos, la preocupación con la temática mencionada adquiere importancia en su desenvolvimiento. Así, aún cuando por vías diferentes, la discusión sobre el psicologismo termina siendo central en las tres tradiciones.

La perspectiva analítica es "objetivista". El dato a ser reflexionado es el lenguaje y, eventualmente, la significación lingüística. La subjetividad del sujeto sólo es tema en tanto lenguaje que tematiza la misma, pero no en lenguaje objeto, como factor productor o condición del propio lenguaje.

Como ya indicamos, la perspectiva fenomenológica es, por el contrario, esencialmente "subjetiva". Ahora, como debería ser obvio, mas no lo es, un abordaje subjetivo no implica "psicologismo", ${ }^{30}$ por el contrario: si la formulación de la idea de objetividad no-real es condición sine qua non para fijar el concepto de significado en su especificidad, ella torna necesario un nuevo problema del sujeto característicamente diferente del moderno y en el cual la cuestión de la trascendencia cambia su eje del mundo real al ideal-objetivo. ${ }^{31}$ Este nuevo problema no se plantea (ni puede plantearse) en el psicologismo, dado que él consiste en negar la trascendencia mencionada, mas se coloca de modo ineluctable como consecuencia de su superación, siendo esta, por tanto, supuesto de la temática fenomenológica de la subjetividad (una temática, por tanto, no pres- sino posfregueana).

Fenomenología y hermenéutica encuentran en el trazo subjetivo un elemento común. En ambas no es el concepto de sentido en sí lo que preocupa de modo primario, sino siempre el sentido vinculado a la vivencia de su aprehensión, sea ésta un "entender" (Verstehen) o un captar (Auffassen). ${ }^{32}$ No obstante, en la similitud mencionada se contiene, al mismo

29 En realidad, existen diferentes tipos de psicologismo y antipsicologismo (lógico, epistemológico, semántico, etc.).

30 La confusión que aquí se produce se debe en buena medida a no diferenciar el concepto de psicologismo de Frege y de Wittgenstein.

31 Este problema ya está presente en Frege de modo explícito. 
tiempo, una diferencia. El sujeto de la hermenéutica es algo heterogéneo de aquel de la fenomenología; su relación al "objeto" no es pensada a partir de la noción de esencias, sino de facticidad.

De la superación del psicologismo por Frege, la filosofía analítica se dirige, con Wittgenstein, a una critica radical del solipsismo metódico y del conciencialismo en general. La fenomenología recorre un camino comparable: la crítica de la subjetividad moderna se constituye en tema central de reflexión. ${ }^{33}$ A la hermenéutica, por su parte, corresponde el mérito de haber dado inicio a tal revisión. De este modo, en el momento inicial y final del desarrollo de las tres tradiciones hay coincidencia, por un lado en la discusión en torno al psicologismo y en la preocupación con la objetividad de la significación, por otro, en la crítica radical del conciencialismo y del sujeto de la modernidad.

\section{El punto de vista metódico}

Si existe hoy una tendencia incipiente a establecer vínculos entre filosofía analítica, fenomenología y hermenéutica, existe también una reacción que procura mantener, sobre todo por una razón eminentemente metodológica, el hiato entre las tradiciones mencionadas. La más seria objeción que se puede dirigir a nuestra tesis es que ella se concentra unilateralmente en la perspectiva temática, subestimando la consideración metódica. Ahora bien, aquí existirá siempre un abismo insalvable entre una filosofía que se concibe a sí misma como análisis del lenguaje y otra que o pretende una consideración inmediata de los pensamientos o reincide en el examen introspectivo. ${ }^{34}$ La línea demarcatoria entre filosofía analítica y no analítica debe ser fijada sobre la base del principio de que, para la primera sólo es posible un estudio de los "pensamientos" (Gedanken) a través de un análisis del lenguaje. ${ }^{35}$

\footnotetext{
32 Lógicamente que esta perspectiva subjetiva presenta variaciones en las diferentes fases de la fenomenología, tendiendo a ser reformulada a partir de la confluencia con la hermenéutica. La temática del "mundo vital" (Lebenswelt) llevará a una posterior aproximación en este punto.

33 Ryle sigue atentamente el desenvolvimiento de la fenomenología a través de Merleau-Ponty.

34 Obviamente que esta colocación, la cual tiene sus buenas razones en cuanto referida a la fenomenología, no es sin más válida para la hermenéutica, aún cuando pueda ser reformulada de manera tal que la atinja.

35 Entendemos aquí por "pensamiento" lo pensado por contraposición al pensar, el contenido por contraposición al acto, sea cual sea el status otorgado al mismo, con tal que él posea estructura proposicional.
} 
El argumento de la irreductibilidad metódica merece detenido estudio. Él es, sin duda, un buen argumento contra aquellos que buscan aproximar la filosofía analítica a la fenomenología de un modo tal que minimizan las diferencias entre ambas. Sin embargo, el no es un buen argumento contra nuestra tesis, la cual no desconoce la alteridad aquí presente sino que la redimensiona a partir de la afirmación de la existencia de un núcleo común. ${ }^{36}$

Existe una mitología de lo puramente metódico, similar a aquella de lo puramente "dado". Métodos, sin embargo, no son nunca inocentes. Todos ellos implican, al mismo tiempo, compromisos teóricos, un ámbito temático-conceptual, no menos que objetivos o tareas que les dan sentido. Justamente por ello, existe una limitación intrínseca a todo proceder metódico: ni él puede dejar de presuponer, ni él puede justificar aquello que presupone. El análisis lógico del lenguaje no es una excepción de este principio, sino que lo confirma. Este hecho queda oculto por el acento dado a la idea del lenguaje como "límite", a la imposibilidad de su "ultrapasaje" (Nichthintergehbarkeit) y a su carácter último (Letztheit), de forma tal que el análisis se presenta como la culminación de la propia idea de método y, con ella, de la pretensión filosófica básica de reflexividad radical. El no supone "nada" en la medida en que es capaz de tematizar "todo" (lo que se puede tematizar, o sea, lo que se puede “decir”). Pero, ¿qué es ése lenguaje no ultrapasable con el cual se ocupa el método semántico? Ciertamente, no es el lenguaje como fenómeno de la naturaleza, sino como "medio universal". En consecuencia, el análisis lingüístico requiere de un criterio identificador de su objeto. Ahora bien, tal criterio no es posible de principio sin la idea de "significación", siendo la misma, por tanto, imprescindible para fijar aquello a ser analizado. "Significación" es parte del repertorio conceptual con el cual la filosofía analítica fija su objeto y, en consecuencia, presupuesto del método lingüístico. ${ }^{37}$

Si el objetivo de la oposición mencionada al comienzo del numeral es establecer en qué consiste la diferencia primera del análisis lingüístico con todo otro modo de hacer filosofía, entonces, tenemos que decir que

36 Mas allá de lo expuesto, levanto la hipótesis (que en modo alguno pretende ser elemento fundamental en el argumento desenvolvido) de que, así como en los últimos años há habido una aproximación entre las tres líneas principales de la filosofia contemporánea, también há habido una cierta confluencia metódica. Tres puntos merecen atención en tal sentido:

a) remplazo de lo privado por lo público;

b) substitución de la "teoría" por la actividad;

c) explicitación de sentido como condición de todo proceder.

37 Esta idea del significado no es aún teoría del significado. 
este objetivo no es alcanzado. El punto de partida dista de ser obvio, no quedando en claro, en qué se sustenta, a no ser que, implícitamente, se tenga ya en vista al análisis lógico como culminación de la historia del pensamiento. En efecto, se da por concedido que la filosofía es análisis de los pensamientos y, sobre la base de este presupuesto, se plantea una alternativa entre dos formas de efectivar al mismo. Sin embargo, ni en el periodo ontológico, ni en el epistemológico, la filosofía fue concebida como "análisis del pensamiento" (sino como análisis del objeto o de nuestro conocimiento del mismo). En consecuencia, para que tenga sentido fijar en el seno de la filosofía una línea demarcatoria exhaustiva y suficiente entre dos formas del análisis de los pensamientos, se debe ya presuponer la idea de que la filosofía es análisis del pensamiento, no menos que la propia noción de "pensamiento". Ahora bien, justamente ése es el punto, pues para aceptar esos dos presupuestos, el establecimiento de la noción de sentido y su distinción de la del valor de verdad es esencial. Si esto es así, el criterio en cuestión fija una delimitación inequívoca de lo que sea la filosofía analítica en el marco de la filosofía contemporánea, aún cuando, justamente por ello, no establece unos hiatos con las otras corrientes de la misma, sino una diferencia sobre el trasfondo de una coincidencia.

Con respecto al método fenomenológico y al hermenéutico, vale algo similar que con respecto al analítico: tanto la propuesta metódica de la fenomenología, cuanto de la hermenéutica, presuponen el concepto de significación como horizonte en el cual son inteligibles.

En síntesis, debe concederse que, entre las tres líneas principales de la filosofía contemporánea, existe irreductibilidad metódica. Con todo, la constatación de este hecho no compele a afirmar la existencia de un hiato absoluto entre las mismas. La diferencia metódica es justamente consecuencia de un marco temático compartido dado por el concepto de significación y con respecto al cual ellas constituyen opciones diversas. El reconocimiento de la irreductibilidad metódica es, por tanto, un argumento que no sólo no invalida nuestra tesis sino que, por el contrario, la confirma desde una perspectiva inesperada.

\section{Consideración final}


A través de las páginas que antecedieron hemos procurado transmitir al lector una forma de ver la filosofía contemporánea diversa a aquella mayoritaria en nuestros días.

1 Esencial en nuestra tesis es la afirmación de la conmensurabilidad entre filosofía analítica y fenomenológico-hermenéutica. De lo que se trata no es de eliminar toda diferencia, sino de superar la idea de un abismo irreducible entre las tres tradiciones, la cual, de modo irreflexivo y no tematizado, está en la base de la recíproca ignorancia y el mutuo desprecio.

2 Lo dicho implica, en el ámbito programático, el restablecimiento del diálogo entre las mismas, diálogo que aún existía en un comienzo y que se perdió posteriormente. Tal propuesta, sin embargo, está lejos de ser un llamado a la buena voluntad, un bien intencionado aún cuando ingenuo "seamos amigos". La posibilidad de diálogo es objetiva, dada por la existencia de un sustrato temático común que posibilita la traducción de problemas de una tradición en los términos de la otra.

3 La conmensurabilidad temática, sin embargo, no es sino la manifestación superficial del hecho que, desde el punto de vista de la historia de la filosofía, semántica, hermenéutica y fenomenología son momentos heterogéneos de un mismo "giro" (turn), manifestaciones diversas de un proceso unitario justamente en cuanto diferentes. No sólo afirmamos, pues, que hay un núcleo temático básico común sino, asimismo, que ella manifiesta el mismo "giro" fundamental en la historia del pensamiento. La propia irreductibilidad metódica, que debe ser sin duda concedida, no contradice sino que por, el contrario, confirma este hecho.

Si nuestras tesis se opone en general a un cierto consenso hoy vigente, se oponen en particular a la explícita mitología analítica. La visión de la filosofía contemporánea y de su vínculo con la historia de la filosofía que en ella se contiene, difiere de la que hemos esbozado en dos puntos principales:

1 Para el pensador analítico, la oposición que caracteriza el pasaje del período moderno al contemporáneo es la referente a filosofía del lenguaje - filosofía de la conciencia. Lo que hemos llamado "período epistemológico" no es para él, sino "filosofía de la conciencia", siendo que, aquello que en el problema moderno del conocimiento era legítimo, se disuelve en semántica, lo que era ilegítimo, deviene sicología no-filosófica. 
2 Dado que, por otra parte, para el pensador analítico, la oposición filosofía de la conciencia - filosofía del lenguaje es exhaustiva, el no puede entender el proceder fenomenológico (y, en general, cualquier otra forma de filosofía que no sea la propia) ya que no como filosofía del lenguaje, entonces como filosofía de la "conciencia" (que en nada se diferencia de la moderna, sino que es simplemente una prolongación de ella, en definitiva, un remanente arcaico, un fósil conceptual). De esta forma, la filosofía analítica establece un corte absoluto no sólo con las otras tendencias contemporáneas, sino con la propia historia de la filosofía, corte absoluto que, definiendo su vínculo con la misma como pura negación, intenta fundar un egocéntrico y autosuficiente a-historicismo. ${ }^{38}$

Lo que diferencia el esquema analítico del propuesto en este ensayo, es que éste, al ser más englobante, posibilita ver un punto de unión donde, de otro modo, no habría sino pura alteridad, restituyendo así no sólo la unidad de la filosofía contemporánea, sino de ésta con la historia de la filosofía y, por tal motivo, de la filosofia misma. Al fin de cuentas, ¿porqué el interés en la mediación? Nada más y nada menos que para restablecer la unidad de la filosofia en la perspectiva de su historia.

La marcha de la filosofía asemeja aquella del cangrejo: avanza en cuanto retrocede. Ella no es progresiva en el sentido de acumulación gradual de verdades, ni constructiva en el sentido de articulación de un sistema de las mismas. Ambas cosas pueden, eventualmente, acontecer "también" en la filosofía, no obstante, no constituyen su esencia ni, mucho menos, la razón esencial de su devenir. La construcción sistemática, la derivación de consecuencias, la "solución de problemas", los "discursos argumentativos", son internos a las tradiciones ya constituidas, signos de una "virada" (turn) ya efectuada, pero no fundan un nuevo comienzo en la historia del pensamiento. Ellos son posibles sólo como desenvolvimientos epigonales, no propiamente como "pensar" originario. El "progreso" en filosofía camina en la dirección de la explicitación; la identificación de supuestos (tanto lógico-veritativos cuanto hermenéuticos) es el impulsor de su historia. En cada nuevo período filosófico se tematiza aquello que era aceptado de modo tácito, aún cuando necesario, en el período anterior. ${ }^{39}$ También el período ontológico y el epistemológico-trascendental trabajaban de esta forma. ${ }^{40}$ En éste sentido hay un esencial elemento de unión de la filosofía contemporánea con la his-

38 También aquí la situación ha experimentado grandes cambios en los últimos veinte años. 
toria de la filosofía. La "virada" al significado es un momento más en la larga historia de la explicitación.

Podemos invertir, en nuestro punto de llegada, nuestro punto de partida. Partimos de buscar la unidad de la filosofía contemporánea subyacente a su diversidad. Terminamos aprendiendo que esta unidad nada más es que la unidad de la propia filosofía para la cual le es esencial su historia.

San Pablo, diciembre de 2001

GONZÁLEZ PORTA, M. A. What is “contemporary philosophy”? (The unity of contemporary philosophy from the point of view of the history of philosophy). Trans/Form/Ação (São Paulo), v.25, p.29-52, 2002.

- ABSTRACT: Twentieth-century philosophy split into two traditions that often, at least as a matter of fact, regard each other as incommensurable. The last twenty years pointed to the reversal of this trend. This article can be seen as a contribution to that tendency, in so far as, in it, a new approach to the contemporary reflexion as a whole is proposed: logical analysis and phenomenologyhermeneutics are different sides of one and the same turn in the history of philosophy. Such reading not only recovers philosophy's lost unity, but also throws light on its continuity with history of philosophy.

- KEYWORDS: History of philosophy; contemporary philosophy; analytic philosophy; phenomenology; hermeneutics.

\section{Referencias bibliográficas}

APPEL, K.-O. Transformation der Philososphie. Frankfurt: Suhrkamp, 1976. 2v. v.1: Szientistik, Hermeneutik, Dialektik.

COBB-STEVENS, R. Husserl and analytic philosophy. Dordrecht: Kluwer, 1990.

39 Obsérvese que no se trata de cualquier supuesto, sino de supuestos necesarios.

40 Aún cuando lo hacían de un modo o en una variante "fundacionalista". Diferenciamos "fundamentación" (esto caracteriza la variante metafísica y la transcendental) de "explicitación". Fundamentación es explicitación de presupuestos lógicos, explicitación en general es explicitación de supuestos significativos. La explicitación, en el caso límite, puede asumir el carácter de fundamentación, pero no necesariamente. 
COFFA, A. J. The semantic tradition from Kant to Carnap. Cambridge: Cambridge University Press, 1991.

CREMASCHI, S. Filosofia analitica e filosofia continentale. Firenze: La Nuova Italia, 1997.

DUMMETT, M. Ursprünge der analytischen Philosophie. Frankfurt: Suhrkamp, 1992.

. The interpretation of Frege's Philosophy. Cambridge: Harvard University Press, 1981.

GLOCK, H.-J. The rise of analityc Philosophy. Oxford: Blackwell, 1997.

GONZÁLEZ PORTA, M. A. Transzendentaler Objektivismus. Bruno Bauchs kritische Verarbeitung des Themas der Subjektivität und ihre Stellung innerhalb der Neukantianischen Bewegung. Frankfurt: Peter Lang, 1990.

. Von Newton bis Maxwell. Objektivität in der Kantischen und Neukantianischen Wissenschaftstheorie mit besonderer Berücksichtigung von Cassirers Projekt einer "Philosophie der symbolischen Formen". In: ENGSTLER, A., KLEIN, H. D. (Org.) Perspektiven und Probleme systematischer Philosophie. Berna: Peter Lang, 1996. p.77-93.

. Cassirer und Kant. Cassirer - Forschungen II. Berlin: Meiner Verlag, 1996.

. La teoría del número en Natorp y Cassirer (1898-1910) - (Una contribución histórica al estructuralismo matemático y a los orígenes del 'semantic turn'). Themata (España), v.XVII, p.199-222, 1996.

. Los orígenes de la virada antipsicologista en Husserl (La reseña a Schroeder de 1891 revisada). Themata (España), v.XXI, p.85-117, 1999.

. La cuestión noética en Frege, su concepto de intencionalidad y su influencia sobre Husserl. Una contribución al estudio de los orígenes de la filosofía contemporánea. Themata (España), v.XXIV, p.83-115, 2000.

Equivocidad del ser y objeto intencional. Kriterion, n.105, p.97-118, 2002 .

Platonismo e intencionalidade: a propósito de Bernhard Bolzano. Sintese (nova fase). (No prelo).

O'HEAR, A. German Philosophy since Kant. Cambridge: Cambridge University Press, 1999.

PICARDI, E. La chimica dei concetti. Linguaggio, logica, psicologia 1879-1927. Bologna: Il Mulino, 1994.

WRIGHT, H. G. von. Analytische Philosophie - eine historisch-kritische Betrachtung. In: MEGGLE, G. (Org.) Analyomen II. Akten der zweiten Kongress der Gesellschaft für analytische Philosophie (GAP). Berlin: Gruyter, 1994. p.1-24. 